Sammlung Metzler

Band 116 


\section{Das deutsche}

\section{bürgerliche Trauerspiel}

5., überarbeitete und erweiterte Auflage

Verlag J.B. Metzler

Stuttgart - Weimar 
1. Auflage 1972 (1.-5. Tsd.)

2. Auflage 1976 (6.-10. Tsd.)

3. Auflage 1980 (11.-15. Tsd.)

4. Auflage 1984 (16.-20. Tsd.)

5. Auflage 1994 (21.-25. Tsd.)

CIP-Kurztitelaufnahme der Deutschen Bibliothek

Guthke, Karl S.:

Das deutsche bürgerliche Trauerspiel / Karl S. Guthke.

- 5., überarb. und erw. Aufl., (21. - 25. Tsd.).

- Stuttgart ; Weimar : Metzler, 1994

(Sammlung Metzler ; M 116 : Abt. D, Literaturgeschichte)

ISBN 978-3-476-15116-2

NE: GT

ISSN 0058-3667

ISBN 978-3-476-15116-2

ISBN 978-3-476-04144-9 (eBook)

DOI 10.1007/978-3-476-04144-9

SM 116

Dieses Werk einschließlich aller seiner Teile ist urheberrechtlich geschützt. Jede Verwertung außerhalb der engen Grenzen des Urheberrechtsgesetzes ist ohne

Zustimmung des Verlages unzulässig und strafbar. Das gilt insbesondere für Vervielfältigungen, Übersetzungen, Mikroverfilmungen und die Einspeisung und Verarbeitung in elektronischen Systemen.

(C) 1994 Springer-Verlag GmbH Deutschland Ursprünglich erschienen bei J.B. Metzlersche Verlagsbuchhandlung und Carl Ernst Poeschel Verlag GmbH in Stuttgart 1994 


\section{Inhalt}

Abkürzungen ………………………………………..... VI

Vorwort zur zweiten Auflage .................................................. VII

Vorwort zur fünften Auflage .................................................. VIII

I. Einführung: Bürgerliches Trauerspiel - eine literarische Gattung? ......................................................... 1

II. Anfänge und Grundlagen .................................................. 6

1. Wort und Begriff in der Entstehungszeit ........................ 6

2. Geistes- und literaturgeschichtliche Bedeutung des bürgerlichen Trauerspiels .......................................... 17

3. Vorgeschichte in Deutschland ………………………. 22

4. Ausländische Anregungen ............................................ 28

III. »Miß Sara Sampson« und die Folgen ............................. 39

1. Empfindsamkeit und Bürgerlichkeit ............................. 39

2. Die Theorie des "Privat-Trauerspiels «........................... 46

3. Das empfindsame bürgerliche Trauerspiel ..................... 54

IV. Von »Emilia Galotti« bis »Kabale und Liebe« ............ 73

1. Standesbewußtsein und Gesellschaftskritik .................... 73

2. Lessing und die Sozialpolitisierung
des bürgerlichen Trauerspiels ....................................... 79

3. Spielarten des bürgerlichen Trauerspiels im Sturm und Drang ........................................................ 86

V. Verfall, Wandlung, Nachspiele ..................................... 101

1. Schwundformen in der Goethezeit ........................... 101

2. Das bürgerliche Tendenzdrama des Jungen Deutschland ............................................. 105

3. Hebbel und die "Tragödie des Bürgertums« ................ 110

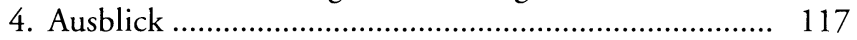

Namenregister …………………………………………..... 123 


\section{Abkürzungen}

Abt.

ADB

bgl.Tr.

Diss.

DLD

$\mathrm{dt}$.

DVjs.

GLL

GRM

hrsg.

Jb.

JEGP

Jh.

Lachmann/Muncker

Masch.

MLN

MLR

NDB

N.F.

Petersen/Olshausen

RL

Tgb.

Zs.

Abteilung

Allgemeine Deutsche Biographie

bürgerliches Trauerspiel

Dissertation

Deutsche Literatur-Denkmäler

deutsch

Deutsche Vierteljahrsschrift für Literaturwissenschaft und Geistesgeschichte

German Life and Letters

Germanisch-Romanische Monatsschrift

herausgegeben

Jahrbuch

Journal of English and Germanic Philology

Jahrhundert

G.E. Lessing, Sämtliche Schriften, hrsg. v. Karl

Lachmann. 3. Aufl. besorgt von Franz Muncker.

23 Bde. 1886-1924.

Maschinenschrift (ungedruckt)

Modern Language Notes

Modern Language Review

Neue Deutsche Biographie

Neue Folge

G.E. Lessing, Werke. Vollst. Ausg. in 25 Teilen, hrsg. v. Julius Petersen u. Waldemar v. Olshausen. [1925-35].

Reallexikon der dt. Literaturgeschichte

Tagebücher

Zeitschrift 


\section{Vorwort zur zweiten Auflage}

Für die Neuauflage wurden die Bibliographien auf den neusten Stand gebracht und die Textpartien einer gründlichen stilistischen und sachlichen Revision unterzogen. Dieser sind nicht nur die Besprechungen der ersten Auflage und die neueren Arbeiten zum bürgerlichen Trauerspiel sowie zu einzelnen Exemplaren der Gattung zugute gekommen, sondern auch die eigenen Studien der letzten Jahre, die zu meinem Buch "Literarisches Leben im 18. Jahrhundert in Deutschland und in der Schweiz" (Bern u. München: Francke, 1975) geführt haben.

Der Anforderung dieser Realienbuch-Reihe: kritische Information zu bieten, Urteil und Unparteilichkeit zu verbinden, ist in einer Darstellung des deutschen bürgerlichen Trauerspiels nicht leicht zur Zufriedenheit aller Kritiker zu genügen, da das bürgerliche Trauerspiel für viele ein Politikum geworden ist. Was den einen als Fairneß berührt, wirkt auf andere als Zuviel oder Zuwenig an Parteilichkeit. Davon unangefochten, habe ich es jedoch für angezeigt gehalten, meine grundsätzliche Skepsis gegenüber der landläufigen Vorstellung vom bürgerlichen Trauerspiel als kohärenter literarischer Gattung stärker (doch ohne die Verpflichtung zur Sachlichkeit weniger ernst zu nehmen) zu akzentuieren (s. besonders Kap. I) - in der Hoffnung, dadurch ein kritisches Gespräch in Gang zu bringen über die immer noch viel zu wenig durchdachte Fundierung des Begriffs dieser Gattung in unausgesprochenen traditionellen wissenschaftlichen Vorentscheidungen. Für einen kritischen Anstoß in dieser Richtung danke ich außer den Rezensenten, die so freundlich waren, die eigenständige Forschungssubstanz dieses kleinen Handbuchs zu würdigen, besonders Herrn Dr. Reinhart Meyer, der mich auch auf drei als bürgerliche Trauerspiele bezeichnete Stücke sowie auf die Periochen von zwei verschollenen jesuitischen bürgerlichen Trauerspielen aufmerksam machte (s.u. S. 66), die mir in der ersten Auflage entgangen waren.

\section{Harvard University}

Dezember 1975

K.S.G. 


\section{Vorwort zur fünften Auflage}

Die vierte Auflage (1984) dieses Buches, das zuerst 1972 erschien, war lediglich eine bibliographisch leicht ergänzte und in einigen Details korrigierte und erweiterte Fassung der dritten Auflage (1980), die ihrerseits gegenüber der zweiten (1976) und vor allem der ersten eine generelle Überarbeitung darstellte. Die vorliegende fünfte ist wiederum eine in den darstellenden und bibliographischen Partien stark revidierte und ergänzte Bearbeitung der vierten.

Die Druckgeschichte dieses Buches umspannt also das Vierteljahrhundert, in das (nach der ersten Phase des Interesses, vom späten 19. Jahrhundert bis in die dreißiger Jahre des 20.) die entscheidenden Ereignisse in der Erforschung der Gattung des bgl. Tr. fallen. In den sechziger und frühen siebziger Jahren bot sich das bgl. Tr. in erster Linie "als Paradigma für eine literarische Beschäftigung mit Texten an, deren Bedeutung primär in der Spiegelung gesellschaftlicher Umbruchprozesse hervortrat", wie Manfred Durzak es in "Zu Gotthold Ephraim Lessing. Poesie im bürgerlichen Zeitalter" (1984) formuliert hat (S. 133). Es folgten, nach einem gewissen Rückgang des Interesses in den Jahren der wiederentdeckten Innerlichkeit, in den achtziger Jahren besonders die familiengeschichtlich orientierten Studien zu der Gattung, die ja in prononcierter Weise in der Familie statt am Hof oder in der großen Welt beheimatet ist und in dieser Hinsicht der sozialen Realität gerecht zu werden sucht. Zögernd ließen sich auch ein paar mehr formal und im engeren Sinne literarisch orientierte Arbeiten sehen. Um 1990 dann schien der ganze Komplex im wesentlichen hinreichend erforscht zu sein; die Akten waren mehr oder weniger geschlossen, das Examensthema besiegelt, das Wissenswerte übersichtlich geordnet, nicht zuletzt in der vierten Auflage dieses Buches, so ergänzungsbedürftig in Einzelheiten besonders bibliographischer Art es auch mittlerweile erscheinen mochte. Es sah aus, als sei das La Bruyèresche "Tout est dit" erfüllt. Was die in der ehemaligen DDR seit der vierten Auflage weiterhin anhaltende Hochflut sozialhistorisch ausgerichteter Studien noch brachte, war, nicht anders als seit den sechziger Jahren, wenig brauchbares Strandgut, in der Regel ohne ausreichenden Kontakt mit der Forschung, voraussagbar im "Ergebnis», sachlich négligeable. 
Das Thema "Bgl. Tr.» schien reif für postmoderne Zuwendung. Dazu ist es noch nicht gekommen. Vorerst aber, um 1993, hat man vielmehr ernst gemacht mit dem seit langem als berechtigt erkannten, schon in der ersten Auflage dieses Buches ausgesprochenen Wunsch, innerhalb der Gattung bgl. Tr. die Umgebung der allbekannten Spitzenleistungen ("Miss Sara Sampson«, „Emilia Galotti«, "Kabale und Liebe" und noch "Maria Magdalena») genauer kennen zu lernen. Besonders die stofflich reichhaltig fundierten umfassenden Studien von Elena Vogg und Cornelia Mönch haben den explorativen Abstieg vom "Höhenkamm" nicht gescheut - mit interessanten Ergebnissen, die in dieser Neubearbeitung berücksichtigt werden. Gewiß ist das erst ein Anfang, ein Anfang, der auch Probleme aufwirft und auf eben diese Weise weiteren Studien dieser Art den Weg weist. So hat es den Anschein, als werde jetzt eine neue Phase der Erforschung des bgl. Tr. eingeleitet, die ihm erneute Aktualität verspricht.

Harvard University

Sommer 1994

K.S.G. 